\title{
DOI: $10.5846 /$ stxb201212271887
}

韩路, 王家强, 王海珍, 宇振荣. 塔里木河上游胡杨种群结构与动态.生态学报, 2014,34(16) :4640-4651.

Han L, Wang J Q, Wang H Z, Yu Z R. The population structure and dynamics of Populus euphratica at the upper reaches of the Tarim River.Acta Ecologica Sinica, 2014,34(16): 4640-4651.

\section{塔里木河上游胡杨种群结构与动态}

\author{
韩 路 ${ }^{1,2}, *$, 王家强 ${ }^{1}$, 王海珍 ${ }^{1}$, 宇振荣 ${ }^{2}$ \\ (1. 塔里木大学植物科学学院, 阿拉尔 $843300 ; 2$. 中国农业大学资源与环境学院, 北京 100193)
}

\begin{abstract}
摘要:采用样带调查法对塔里木河上游 3 个断面 $8.5 \mathrm{hm}^{2}$ 天然胡杨林进行野外调查,绘制了胡杨种群年龄结构图和存活曲线,结 合种群动态量化方法与时间序列预测, 分析种群结构与动态特征。结果表明: 塔里木河上游胡杨种群密度随径级增大而减小, 自疏指数接近-3/2, 个体胸径达 $24 \mathrm{~cm}$ 后种群密度保持相对稳定。中、下段胡杨种群年龄结构呈金字塔型, 幼龄级所占比例较 大、林分年轻; 存活曲线为 Deevey $\mathrm{C}$ 型, 且动态指数 $>0$, 为增长种群。受所处生境条件影响, 上段不同生境胡杨种群年龄结构差 异明显。阿瓦提县胡杨种群结构呈金字塔型, 幼龄级比例高达 $77.2 \%$, 存活曲线属 Deevey $\mathrm{C}$ 型, 为增长种群; 南口镇与托海乡胡 杨种群结构呈売型, 幼龄级比例极低、中大龄级比例高达 $84.7 \%$, 存活曲线属 Deevey A 型, 为衰退种群; 沙黑里克镇胡杨种群结 构呈钟型, 存活曲线属 Deevey A 型, 为暂时稳定种群。种群数量动态与时间序列分析表明, 中、下段胡杨更新资源丰富,未来种 群能够稳定增长; 上段南口镇、托海乡与沙黑里克镇幼龄级数量随时间推移减少, 种群向大老龄级发展, 未来种群将走向衰退。 总之, 上段胡杨种群因更新资源不足而趋于衰退, 未来保持适当的人工辅助恢复措施和加强保护现有植株及其生境是保持胡杨 种群自然更新和进行种群恢复的关键。
\end{abstract}

关键词 : 塔里木河上游; 不同生境;胡杨种群;年龄结构;动态分析

\section{The population structure and dynamics of Populus euphratica at the upper reaches of the Tarim River}

\author{
HAN Lu $^{1,2, *}$, WANG Jiaqiang ${ }^{1}$, WANG Haizhen ${ }^{1}$, YU Zhenrong ${ }^{2}$ \\ 1 College of Plant Science, Tarim University, Alar, 843300, China \\ 2 College of Resources and Environmental Sciences, China Agricultural University, Beijing 100193, China
}

\begin{abstract}
Desert riparian forest, an important vegetation type in the Tarim River Basin, plays a dominant role in the structure and function of the surrounding desert ecosystem and has a strong influence on the landscape vegetation patterns in the vicinity. Desert riparian forest dominated by Populus euphratica has not only protected the fragile desert ecological system but also served as an irreplaceable natural barrier. P. euphratica is highly prized in the Tarim Basin, Xinjiang Region, China, for its great ecological, economic and social benefits. Land opening campaigns resulted in the destruction of large areas of $P$. euphratica forests after the $1950 \mathrm{~s}$. The excessive use of water for irrigation created a severe threat to the remaining $P$. euphratica forests by robbing them of their source of water. Maintaining the stability of $P$. euphratica populations is important to local development. The objective of this study was to illuminate the current population structure, quantitative dynamics, forest health and the trends for development of the remaining $P$. euphratica forests, with the goal of ensuring the wise use (conservation) and protection (preservation) of the dominant forest tree population in the Tarim River Basin. Plots that covered $8.5 \mathrm{hm}^{2}$ were established in three (upper, middle and lower) sections in the upper reaches of the Tarim River; diameter at breast height $(D B H)$, tree height, crown width and canopy density were measured for stems
\end{abstract}

基金项目:国家自然科学基金(31060066)；973 前期研究专项(2011CB411909，2012CB426507)

收稿日期: 2012-12-27; 网络出版日期:2014-03-04

*通讯作者 Corresponding author.E-mail: hlzky@163.com 
of all trees with a $(D B H)>2.5 \mathrm{~cm}$, and trees were classified and identified to species using transect sampling. Graphs of the age structure and survival curves were created, and analysis was conducted of the quantitative population dynamics. Time sequence prediction of future forest conditions was conducted based on field data. The results showed that population density of $P$. euphratica tended to decrease as the size class increased; that is, the value of self-thinning was close to $-3 / 2$ and the population density would remain relatively stable when the $D B H$ exceeded $24 \mathrm{~cm}$. The age structure of $P$. euphratica populations had a positive pyramidal type, with a high percentage of younger age-class individuals. At the middle and lower sections, the survivorship curve of $P$. euphratica populations conformed to Deevey C type ( concave-type) with the dynamic indices $\left(V_{p i}\right)>0$ indicating that the $P$. euphratica populations were expanding. The environmental conditions in the upper section were much different from those of the middle and lower sections of the upper reaches of the Tarim River; populations in the upper section developed different characteristics and age structures from the other two sections. In Awti County, the age structure of the $P$. euphratica population was a positive pyramidal type and younger age-class individuals accounted for $77.22 \%$ of the total; the survivorship curve conformed to Deevey $\mathrm{C}$ and the structure was an expanding population. In Nankou and Tuohai towns, the age structure of the populations was a constrictive pyramid, with lower ratios of younger ageclass to older individuals, while the ratio of adult individuals reached $84.7 \%$ of the population. The survivorship curves were classified as Deevey A (convex) type and structures indicated declining populations. In Shaheilike town, the age structure of $P$. euphratica populations was the bell type, the survivorship curve conformed to Deevey A type, and structure indicated a temporarily stable population. The analysis of the quantitative dynamics and time sequence prediction for $P$. euphratica populations in the next 10,20 and 30 years indicated that $P$. euphratica populations would grow steadily in the future as a result of rich seedling resources in the middle and lower sections. The younger age-class individuals of $P$. euphratica populations would decrease in numbers and numbers of old individuals would significantly increase in the upper section. The populations were declining during ecological succession in Nankou, Shaheilike and Tuohai towns. Limited recruitment in $P$. euphratica populations, caused by habitat degradation and the withdrawal of water for irrigation, may affect the persistence of this species and the long-term dynamics of the forest in the upper section. Therefore, protection of existing living trees and their habitats is important to the sustainable development of $P$. euphratica forests in the upper reaches of the Tarim River.

Key Words : the upper reaches of Tarim River; different habitats; $P$. euphratica population; age structure; dynamic analysis

种群结构是种群最基本的特征, 它既可反映种 群内不同大小个体数量的分布和配置状况, 也能反 映种群的数量动态及其未来发展与演变趋势 ${ }^{[1]}$ 。植 物种群在不同生境条件下的年龄结构、存活曲线和 生命表不仅可以反映现在的种群状态, 而且还可以 反映植物与环境之间的适合度 ${ }^{[2]}$, 分析过去种群结 构与受干扰状态, 预测未来的种群动态 ${ }^{[3]}$ 。因此, 研 究种群结构及其动态, 有助于人们更好地认识种群 的生态特性、影响因素、形成机制、稳定性与演替规 律, 揭示种群和环境之间的关系及其在群落中的地 位和作用, 对种群及群落的更新复壮、生态系统的恢 复具有重要意义。

胡杨 (Populus euphratica Oliv.) 是杨柳科杨属中
最古老、最原始的木本植物 ${ }^{[4-5]}$, 也是新疆塔里木河 流域主要的优势树种和珍贵的抗逆种质资源。胡杨 种群是整个塔里木河流域植被中非常重要的组成部 分, 其对遏制沙化、维护区域生态平衡和保障绿洲农 牧业生产及生态环境可持续性发展起着重要作用。 但近年来由于塔里木河上游大规模水土资源开发利 用, 河流两岸地下水位持续下降, 导致沿河两岸天然 植被大幅削减和破坏、种群生长不良与数量锐减 ${ }^{[6]}$ 。 目前, 国内外对塔里木河中、下游胡杨种群生态特征 已有较多研究报道 ${ }^{[7-9]}$, 但有关塔里木河上游胡杨种 群结构与数量动态的系统研究少见报道。因此, 本 文通过对塔里木河上游荒漠河岸林胡杨种群的年龄 结构、数量动态特征与生存状况进行定量研究, 预测 
种群未来的发展趋势并揭示其形成原因,探索影响 不同生境种群动态的内外因素, 以期为塔里木河流 域天然胡杨林的恢复、生态环境保护与重建及水资 源的高效利用、区域社会经济可持续发展提供科学 决策依据。

\section{1 研究区概况}

塔里木河上游系指从阿克苏河、叶尔芫河、和田 河三河交汇的肖夹克至轮台县的英巴扎, 总长 495 $\mathrm{km}$ (图 1)。该区经纬度 $40^{\circ} 25^{\prime} \mathrm{N}, 80^{\circ} 10^{\prime} \mathrm{E}$ 至 $41^{\circ} 10^{\prime}$ $\mathrm{N}, 84^{\circ} 36^{\prime} \mathrm{E}$; 平均日照时数 $2729.0 \mathrm{~h}$, 太阳总辐射能 $5796 \mathrm{MJ} \mathrm{m}^{-2} \mathrm{a}^{-1}$, 年平均气温 $10.4{ }^{\circ} \mathrm{C}, \geqslant 10{ }^{\circ} \mathrm{C}$ 年积温 $4340{ }^{\circ} \mathrm{C}$, 平均气温 $\geqslant 10{ }^{\circ} \mathrm{C}$ 的持续日数为 $201 \mathrm{~d}$, 极端
最高温度 $39.4{ }^{\circ} \mathrm{C}$, 极端最低温度 $-25.0{ }^{\circ} \mathrm{C}$ 。年平均 降水量 $50.4 \mathrm{~mm}$, 年平均蒸发量 $1880.0 \mathrm{~mm}$, 干燥度 12-19。风沙灾害频繁,春、夏季多大风天气, 是该 地区风沙危害的主要季节。该区植被组成简单、稀 疏,乔灌草三层结构明显。乔木主要有胡杨、灰胡杨 (Populus pruinosa); 林下植物主要有多枝柽柳 ( Tamarix ramosissima)、黑果枸 杞 (Lycium ruthenwum)、铃铛刺 (Halimodendron halodendron)、芦 苇（Phragmites australis）、罗布麻（Apocynum venetum)、甘草(Glycyrrhiza uralensis)、骆驼刺(Alhagi sparsifolia)、西北天门冬 (Asparagus persicus)、小花棘 豆( Oxytropis glabra) 等植物。

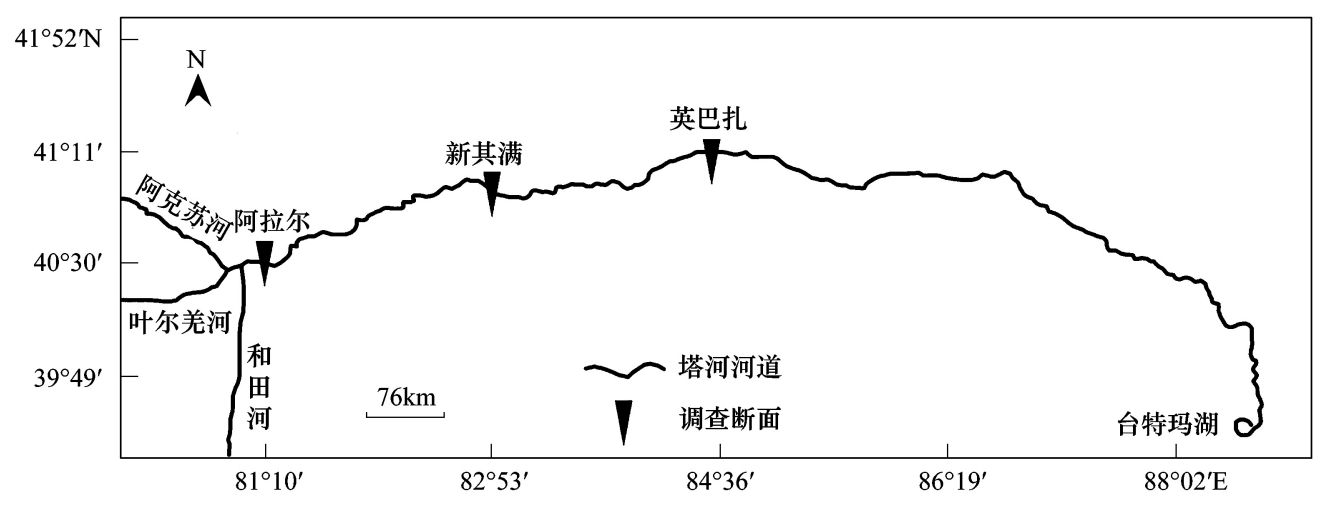

图 1 塔里木河上游调查断面示意图

Fig.1 Investigation sections at the upper reaches of the Tarim River

\section{2 研究方法}

\section{1 样地设置与外业调查方法}

野外充分踏查的基础上在塔里木河上游 (UR)一上段 (A) 阿拉尔、中段 (B) 新其满及下段 (C) 英巴扎断面设立研究点, 选择面积较大、人为干 扰较小、林分具有代表性的天然胡杨林,在林地内选 取 6 个调查地点: $A_{1}$ 阿瓦提县、 $A_{2}$ 托海乡、 $A_{3}$ 南口镇、 $A_{4}$ 沙黑里克镇、 $B$ 沙雅县、 $C$ 轮南镇 (塔河以北), 总 面积 $8.5 \mathrm{hm}^{2}$, 样地环境特征见表 1 。垂直河岸设立 $50 \mathrm{~m} \times 50 \mathrm{~m}$ 的若干样方进行群落调查。在每块样地 内采用相邻格子法进行每木调查, 以 $5 \mathrm{~m} \times 5 \mathrm{~m}$ 为基 本单元, 记录胸径 $(D B H) \geqslant 2.5 \mathrm{~cm}$ 的全部乔木树种 的胸径、树高、冠幅等指标。灌木层 $(4 \mathrm{~m} \times 4 \mathrm{~m})$ 、草 本层 $(1 \mathrm{~m} \times 1 \mathrm{~m})$ 采用对角线法进行植物种类、高度、 盖度、多度等详细调查, 对乔木植物的幼苗、幼树逐 一记录其高度、地径。统计时以胡杨基株为单位进
行统计,若一个树桩上有多个无性系分株,则仅对其 中径级最大的一株进行记录。同时,各样方用 GPS 定位, 记录其经度、纬度和海拔高度、郁闭度等生态 因子。地下水位采用土钻法结合人工打井确定, 土 壤含水量采用土钻分层取土, 铝盒室内烘干法测定。

2.2 种群年龄结构的建立和存活曲线的编绘

胡杨生长周期长, 不可能追踪所有个体的生长 周期,而利用树木年轮精确测定胡杨个体的年龄较 为困难,也缺乏其它可靠的外部特征及解析资料可 以确定其树龄 ${ }^{[1]}$ 。因此,采用空间推时间的方法,应 用生态学中大小结构分析法 ${ }^{[10]}$ 来研究种群年龄结 构特征。虽然种群龄级和径级有所不同,但在同一 环境下,同一树种的龄级和径级对环境的反应规律 具有一致性 ${ }^{[11]}$ 。按照 1960 年森林专业调查办法草 案中的规定并结合胡杨生活史特点, 将种群划分为 12 个径级,第 1 径级胸径为 $0-4 \mathrm{~cm}$,之后每级间隔 $4 \mathrm{~cm}$, 把直径大于 $44 \mathrm{~cm}$ 都归为第 12 级; 第 1 径级对 
应 I 龄级,第 2 径级对应 II 龄级, 依此类推。统计各 龄级株数, 以龄级为纵轴, 株数 $/ \mathrm{hm}^{2}$ 为横轴, 绘制胡 杨种群年龄结构图。树高和冠幅参考于倩 等 $^{[12]}$ 的 方法进行划分: 以 $2.5 \mathrm{~m}$ 作为级差将树高 $(H)$ 划分为 I - VIII8 个等级,其中 I , $H<2.5 \mathrm{~m}$, 依此类推; 冠幅 以树冠的长与宽乘积来表示 ${ }^{[12]}$ 。根据特定时间生
命表的编制方法 ${ }^{[13]}$, 计算生命表中各参数, 绘制存 活曲线。存活曲线是借助存活个体数量来描述特定 年龄死亡率, 它是通过把特定年龄组的相对个体数 量作图而得到。本文以存活量 $l_{\mathrm{x}}$ 为纵坐标, 以龄级 为横坐标作图, 分析种群动态变化。

表 1 塔里木河上游调查样地的环境特征

Table 1 The environmental characteristics of investigated plots at the upper reaches of the Tarim River

\begin{tabular}{lcccccc}
\hline 项目 Item & $\begin{array}{c}\text { 阿瓦提县 } \mathrm{A}_{1} \\
\text { Awati }\end{array}$ & $\begin{array}{c}\text { 托海乡 } \\
\text { Tuohai }\end{array}$ & $\begin{array}{c}\text { 南口镇 } \mathrm{A}_{3} \\
\text { Nankou }\end{array}$ & $\begin{array}{c}\text { 沙黑里克镇 } \mathrm{A}_{4} \\
\text { Shaheilike }\end{array}$ & $\begin{array}{c}\text { 沙雅县 } \mathrm{B} \\
\text { Shaya }\end{array}$ & $\begin{array}{c}\text { 轮南镇 } \mathrm{C} \\
\text { Lunnan }\end{array}$ \\
\hline 经纬度 Latitude and longitude & $40^{\circ} 16^{\prime} \mathrm{N}$ & $40^{\circ} 25^{\prime} \mathrm{N}$ & $40^{\circ} 26^{\prime} \mathrm{N}$ & $40^{\circ} 41^{\prime} \mathrm{N}$ & $40^{\circ} 51^{\prime} \mathrm{N}$ & $41^{\circ} 09^{\prime} \mathrm{N}$ \\
海拔 Altitude /m & $80^{\circ} 22^{\prime} \mathrm{E}$ & $80^{\circ} 56^{\prime} \mathrm{E}$ & $81^{\circ} 09^{\prime} \mathrm{E}$ & $82^{\circ} 00^{\prime} \mathrm{E}$ & $82^{\circ} 10^{\prime} \mathrm{E}$ & $84^{\circ} 12^{\prime} \mathrm{E}$ \\
地下水位 Groundwater level /m & 1031 & 1014 & 1008 & 984 & 972 & 918 \\
土壤盐分 Soil salinity /\% & 3.2 & 2.5 & $2.5-4.0$ & $3.0-4.8$ & $1.5-3.5$ & $1.5-5.2$ \\
土壤含水率 Soil moisture content /\% & 2.51 & 6.66 & 5.86 & 3.73 & 4.65 & 3.56 \\
离河道距离 Distance away from river /m & 10.29 & 19.96 & 9.29 & 3.1 & 25.66 & 13.45 \\
与农田距离 Distance away from farmland /m & 600 & $>2000$ & $>7000$ & $>5000$ & $50-1500$ & $100-3000$ \\
洪水时间 (The time of flood occurrence/month & 700 & 200 & 200 & $>3000$ & $>2000$ & $>1000$ \\
调查时间 Investigation time /month & 8 & 8 & 8 & 8 & 8 & 8 \\
\hline
\end{tabular}

2.3 种群年龄结构数量变化动态指标分析

种群动态是其大小或数量随时间和空间的变 化。根据种群内两相邻龄级间个体数量变化动态 $\left(V_{n}\right)$ 和整个种群年龄结构的数量变化动态指数 $\left(V_{p i}\right)$ 及考虑未来外部干扰时, 种群年龄结构动态 $\left(V_{p i}{ }^{\prime}\right)$, 客观精确地定量比较评价种群结构动态。计 算公式如下 ${ }^{[14]}$ :

$$
\begin{aligned}
& V_{n}=\left(S_{n}-S_{n+1}\right) / \max \left(S_{n}, S_{n+1}\right) \times 100 \% \\
& V_{p i}=\frac{1}{\sum_{n=1}^{k=1} S_{n}} \times \sum_{n=1}^{k=1}\left(S_{n} \times V_{n}\right) \\
& V_{p i}^{\prime}=\frac{\sum_{n=1}^{k-1}\left(S_{n} \times V_{n}\right)}{k \times \min \left(S_{1}, S_{2}, \cdots, S_{k}\right) \times \sum_{n=1}^{k-1} S_{n}}
\end{aligned}
$$

式中, $V_{n}$ 表示种群从 $n$ 到 $n+1$ 级的个体数量变化动 态, $V_{p i}$ 表示整个种群结构的数量变化动态指数, $S_{n}$ 与 $S_{n+1}$ 分别为第 $n$ 与第 $n+1$ 年龄级种群个体数, $K$ 表示 种群最大年龄级, $\max / \min (\cdots \cdots)$ 取括号中数列级 大值/小值, $-1 \leqslant V_{n}$ (或 $\left.V_{p i}\right) \leqslant 1, V_{n}\left(V_{p i}\right)$ 取正、负、零 值时分别反映出种群两相邻年龄级个体数量 (或整 个种群年龄结构) 的增长、衰退、稳定的结构动态关 系 ${ }^{[12]}$ 。当考虑未来外部干扰时, 种群年龄结构动态
$\left(V_{p i}{ }^{\prime}\right)$ 还与年龄级数量 $(K)$ 及各年龄级个体数 $\left(S_{n}\right)$ 有关, 即 $K$ 与 $S_{n}$ 对未来外部干扰存在着 “稀释效 应”, 可由 $K$ 与 $S_{n}$ 根据条件概率法则计算其最大概 率值, 修改为 $V_{p i}{ }^{\prime}$ 式 ${ }^{[14]} 。 V_{p i}{ }^{\prime}$ 也可作为衡量种群结构 动态对随机干扰的敏感性指标。

2.4 种群数量动态的时间序列预测模型

$$
M_{t}=\frac{1}{n} \sum_{k=t-n+1}^{t} X_{k}
$$

式中, $n$ 表示需要预测的未来时间年限, $M_{t}$ 表示未来 $n$ 年时 $t$ 龄级种群大小, $X_{k}$ 为当前 $k$ 龄级的种群大 小。根据现有胡杨种群的年龄结构数据, 应用上式 计算、预测未来种群发展趋势, 原理与方法见 文献 ${ }^{[15-16]}$ 。

\section{3 结果与分析}

\section{1 塔里木河上游胡杨种群年龄结构特征}

塔里木河上游不同生境胡杨种群年龄结构差异 明显, 反映了不同生境对胡杨种群年龄结构的影响 不同(图 2)。上段 $(A)$ 阿瓦提县 $\left(A_{1}\right)$ 天然林胡杨种 群结构呈基部宽顶部窄的金字塔型, 属增长型种群 (图 2)。根据调查数据, 幼苗 ( I )、幼树 (II ) 平均 2051 株 $/ \mathrm{hm}^{2}$, 个体所占比例最大, 达 $77.22 \%$; 中树 
( III-VI ) 较多, 平均 496 株 $/ \mathrm{hm}^{2}$, 占总数 $18.67 \%$; 大 树 ( VII-X) 较少, 平均 99 株 $/ \mathrm{hm}^{2}$, 占总数 $3.73 \%$; 老 树 ( XI-XII) 最少, 平均 10 株 $/ \mathrm{hm}^{2}$, 占总数 $0.38 \%$ 。 表明上游阿瓦提县胡杨种群更新状况较好。随着时 间的推移, 幼龄个体迅速增长, 种群能够稳定增长 下去。
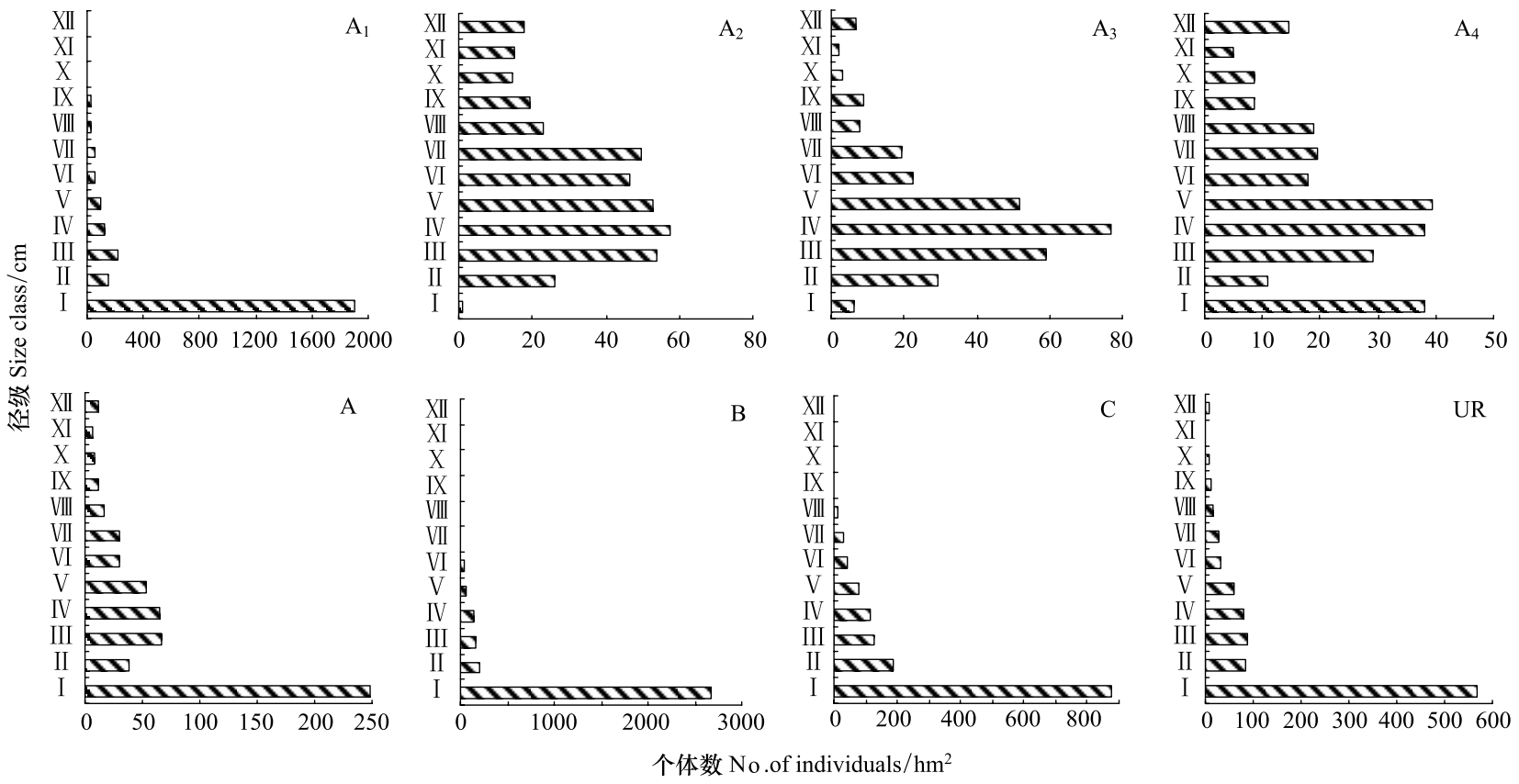

图 2 不同河段与同一河段不同生境胡杨种群年龄结构

Fig.2 Age structure of P.euphratica populations under different sections and different habitats of the same section $\mathrm{A}, \mathrm{B}, \mathrm{C}, \mathrm{UR}$ 表示塔里木河段位

上段南口镇 $\left(\mathrm{A}_{3}\right)$ 天然林胡杨种群结构特征是幼 苗少,仅占总数 $2.04 \%$,幼树、中树、大树与老树分别 占总数 $9.86 \% 、 71.43 \% 、 13.27 \% 、 3.06 \%$ 。年龄结构 大体呈正态分布,龄级集中在 III $-\mathrm{V}$ 级,胡杨林分中 龄偏小,林分稀疏,为衰退种群( 图 2)。

上段沙黑里克镇 $\left(\mathrm{A}_{4}\right)$ 天然林胡杨种群结构完 整。幼苗相对较多,占总数 $15.26 \%$; 幼树、中树、大 树与老树分别占总数 $4.42 \% 、 50.20 \% 、 22.49 \%$ 、 $8.03 \%$ (图 2)。胡杨种群年龄结构近似钟形,幼苗大 多是根蓝苗, 种群暂时稳定。但 II 龄级数量突然急 骤减少, 表明环境中存在严酷的环境篎, 导致 I 龄级 向 II 龄级过渡中死亡率较高 ( 接近 75\%), 这严重影 响着种群的未来发展。

中段 (B) 沙雅县天然林胡杨种群结构呈基部极 宽顶部狭窄的金字塔型, 幼苗数量极丰富, 幼树、中 树、大树与老树分别占总数 $6.06 \% 、 12.09 \% 、 1.56 \%$ 和 $0.15 \%$, 属增长型种群 (图 2)。胡杨种群 I 龄级向 II
龄级发育过程中, 幼龄出现强烈分化现象和自然稀 疏过程,使得幼树个体数量剧减。该胡杨种群的大 龄级极少, 胡杨种群属于中幼龄林阶段。

下段 $(\mathrm{C})$ 轮南镇天然林胡杨种群属增长型, 幼 苗丰富占总数 $58.89 \%$, 幼树、中树、大树与老树分别 占总数 $12.73 \% 、 24.18 \% 、 3.70 \%$ 和 $0.47 \%$ (图 2)。轮 南镇胡杨种群大龄、老龄密度均高于沙雅, 中龄密度 低于阿瓦提县和沙雅县,但所占比例较高。表明轮 南胡杨种群虽然更新良好, 但相比而言其龄级偏大, 未来种群增长潜力不如阿瓦提和沙雅县胡杨种群。

综上所述,整体上塔里木河上游 (UR) 胡杨种群 年龄结构保持完整, 呈典型的金字塔型, 林分年轻、 各年龄级分布合理(图 2)。随着时间的推移, 幼龄 个体迅速增长, 种群能够稳定增长下去, 但上段、中 段与下段胡杨种群结构又存在明显差异 (图 2)。上 段幼苗更新密度明显低于中段与下段, 是中段的 $10 \%$ 与下段的 $28 \%$ 左右, 中树低于中、下段且中龄级 
偏大,大树与老树密度明显高于中、下段, 尤其幼树 （II）显著偏低,结构上出现明显凹陷 (图 2)。表明 上段天然胡杨林立地条件较差, 种群更新能力与幼 树成长能力明显受抑制, 未来种群增长潜力低于中、 下段。分析原因与上段近 20 年大面积旺荒,耕地面 积增长较快, 地表水与地下水过量使用而导致的地 下水位下降及土壤次生盐渍化有关 (表 1)。

3.2 塔里木河上游胡杨种群平均树高、密度与冠幅

上段不同生境胡杨种群密度差异明显,阿瓦提 县胡杨种群密度最高, 沙黑里克镇最低 (图 3)。托 海乡、南口镇与沙黑里克镇种群密度过低导致上段 胡杨密度远低于中、下段(图 3, 表 2)。从表 2 可见,
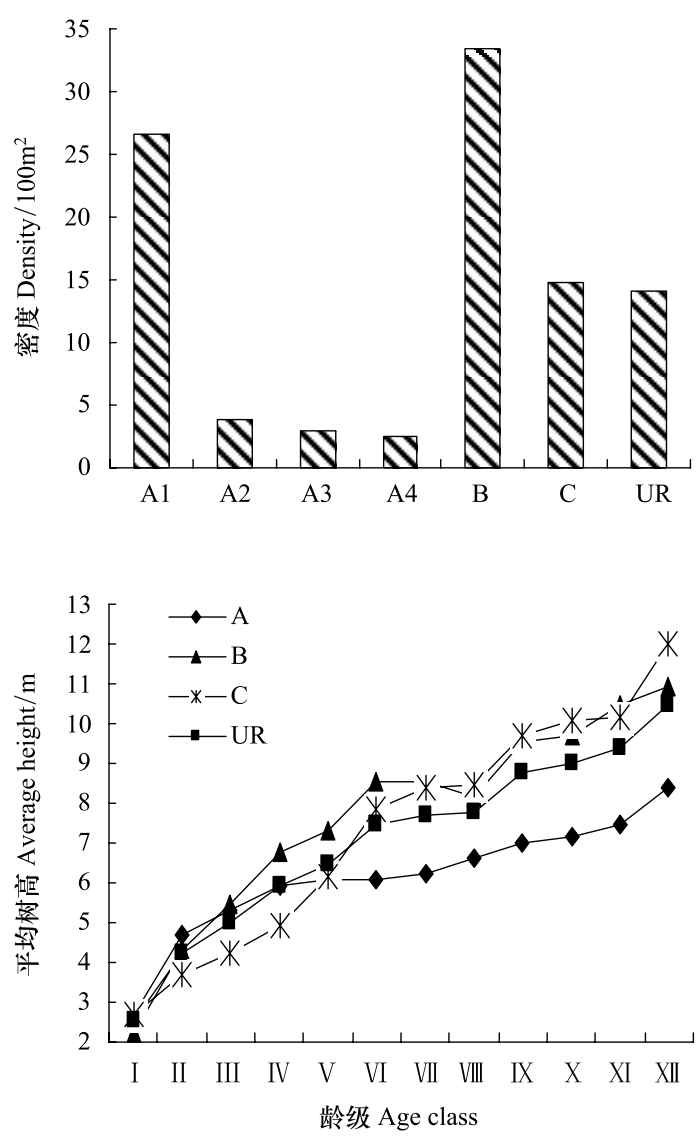

上段胡杨种群平均胸径、平均冠幅与胸高断面最大, 下段居中, 中段最小。中段胡杨种群的平均密度最 大, 为 0.33 株 $/ \mathrm{m}^{2}$, 是下段密度的 2.2 倍和上段的 5.5 倍。从平均树高来看, 上段与下段分别为 $5.57 \mathrm{~m}$ 和 $6.12 \mathrm{~m}$, 主要分布在 II 、III 级, 个体所占比例分别达 $76.00 \% 、 67.48 \%$, 但 I 级个体较少, 仅分别为 $5.09 \%$ 和 $5.83 \%$; 中段平均树高最低, 为 $5.27 \mathrm{~m}$, I 级个体 比例最高为 $33.54 \%$, 是上、下段的 5 倍多, II 级个体 比例占 $36.50 \%, \mathrm{~V}$ 一VIII级比例最低(表 2, 图 3)。表 明中段胡杨高大个体数最少, 下段最多, 上段居中。 上游各段胡杨种群的平均树高、冠幅均随
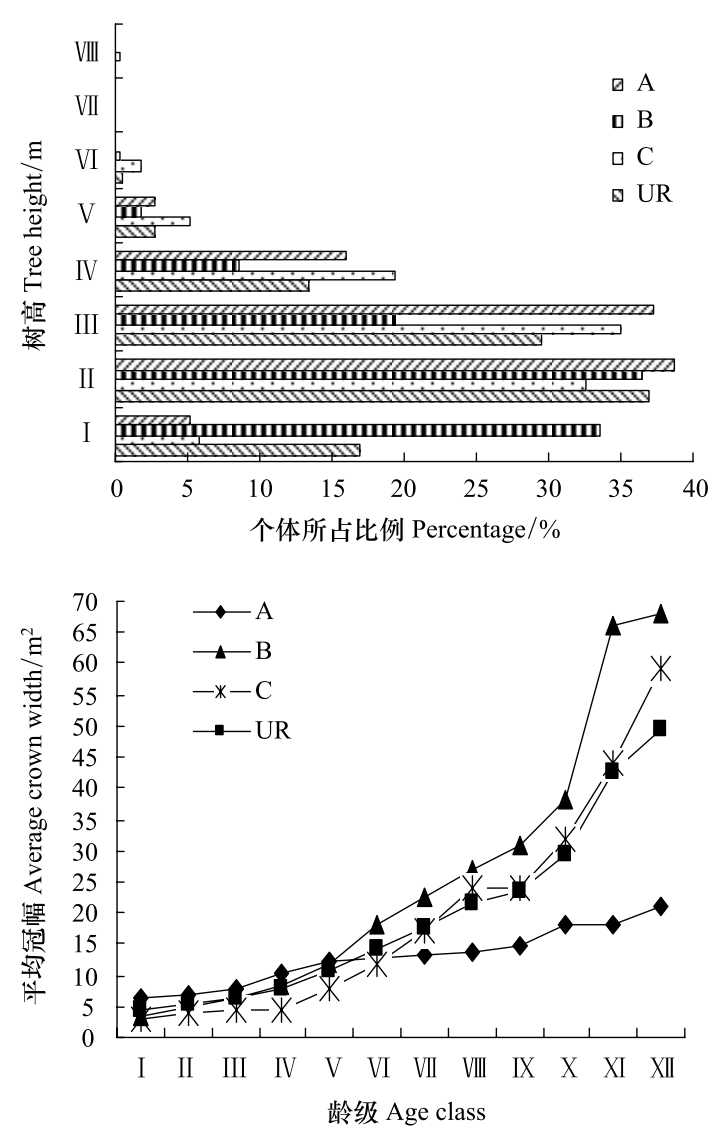

图 3 塔里木河上游不同河段和同一河段不同生境胡杨种群平均树高、冠幅与密度

Fig.3 Average height, density and crown breadth of $P$.euphratica populations under different sections and different habitats of the same section at the upper reaches of the Tarim River

表 2 塔里木河上游不同河段胡杨种群指标统计

Table 2 Parameters of P.euphratica population under different sections at the upper reaches of the Tarim River

\begin{tabular}{ccccc}
\hline $\begin{array}{c}\text { 地点 } \\
\text { Sites }\end{array}$ & $\begin{array}{c}\text { 平均密度 } /\left(\text { 株 } / \mathrm{m}^{2}\right) \\
\text { Average density }\end{array}$ & $\begin{array}{c}\text { 平均胸径 } / \mathrm{cm} \\
\text { Average DBH }\end{array}$ & $\begin{array}{c}\text { 平均树高 } / \mathrm{m} \\
\text { Average height }\end{array}$ & $\begin{array}{c}\text { 平均冠幅 } / \mathrm{m}^{2} \\
\text { Average crown breadth }\end{array}$ \\
\hline A & 0.06 & 18.8 & 5.6 & 11.0 \\
B & 0.33 & 10.2 & 5.3 & 7.7 \\
C & 0.15 & 17.9 & 6.1 & 9.8 \\
\hline
\end{tabular}


龄级的增大而增大 (图 3)。上段、中段与下段的平 均树高、冠幅的差值在 $V$ 龄级之前差异较小, $\mathrm{V}$ 龄级 后差异明显增大(图 3), 尤其中段、下段的平均冠幅 与上段的差值在XI-XII级达到 38-46 $\mathrm{m}^{2}$, 这与上段 生境恶化及个体长势差有关。

\section{3 塔里木河上游胡杨种群密度动态}

塔里木河上游胡杨种群密度随龄级增加而降低 (图 4), 而上段不同生境胡杨种群密度(除阿瓦提县 外)均随龄级增加而增加, 至 IV 级达到最大, 然后随 龄级增大而降低 (图 4)。以种群龄级 $(G)$ 为自变量, 种群密度 $(D)$ 为因变量, 采用幂函数对胡杨种群的 密度动态进行拟合,得回归方程 (表 3 )。从表 3 可 见，上段、中段与下段胡杨种群密度拟合方程均符合 幂函数,但上段不同生境胡杨种群密度拟合方程不 同。总体来看,塔里木河上游胡杨种群自疏指数接
近 $-3 / 2\left(D=571.06 G^{-1.7341}, r=0.9540, P<0.01\right)$ 。塔 里木河上游河漫滩及离河岸近的区域胡杨种群密度 较大, 幼苗较多。随着个体生长, 因自疏作用, 种群 死亡率增加, 使种群密度急剧下降。当群落发展到 一定程度, 通过种内竞争和调节,生态位上开始分 化,并在获取环境资源方面逐渐趋于协调, 自疏作用 减弱,胡杨种群密度趋于稳定。由图 4 可知, 当径级 达到 $24 \mathrm{~cm}$ 以后, 密度保持相对稳定。上段南口镇 与沙黑里克镇胡杨林远离河岸, 土壤沙化明显, 生境 严酷; 托海乡胡杨林则因林分稀疏,较大的林隙被开 垦成农田,林地地表积盐严重,这些因素导致胡杨种 群密度较低, 幼苗匮乏, 出现种群密度随龄级增加呈 上下波动, 径级 $28 \mathrm{~cm}$ 以后种群密度保持相对稳定 (图 4)。

\section{表 3 不同河段与同一河段不同生境胡杨种群密度的拟合曲线}

Table 3 Fitting curve of P.euphratica population density under different sections and different habitats of the same section

\begin{tabular}{ccccc}
\hline $\begin{array}{c}\text { c 地点 } \\
\text { Sites }\end{array}$ & & $\begin{array}{c}\text { 回归方程 } \\
\text { Regression equation }\end{array}$ & $R$ & $P$ \\
\hline $\mathrm{A}$ & $\mathrm{A}_{1}$ & $D=1937.9 G^{-2.2176}$ & 0.9502 & $<0.01$ \\
& $\mathrm{~A}_{2}$ & $D=7.5196 G^{0.6473}$ & 0.4175 & $>0.05$ \\
& $\mathrm{~A}_{3}$ & $D=40.723 G^{-0.6388}$ & 0.4118 & $>0.05$ \\
& $\mathrm{~A}_{4}$ & $D=40.374 G^{-0.5150}$ & 0.5775 & $<0.05$ \\
$\mathrm{~B}$ & & $D=3584 G^{-2.9098}$ & 0.9446 & $<0.01$ \\
$\mathrm{C}$ & & $D=1407 G^{-2.2772}$ & 0.9481 & $<0.01$ \\
\hline
\end{tabular}
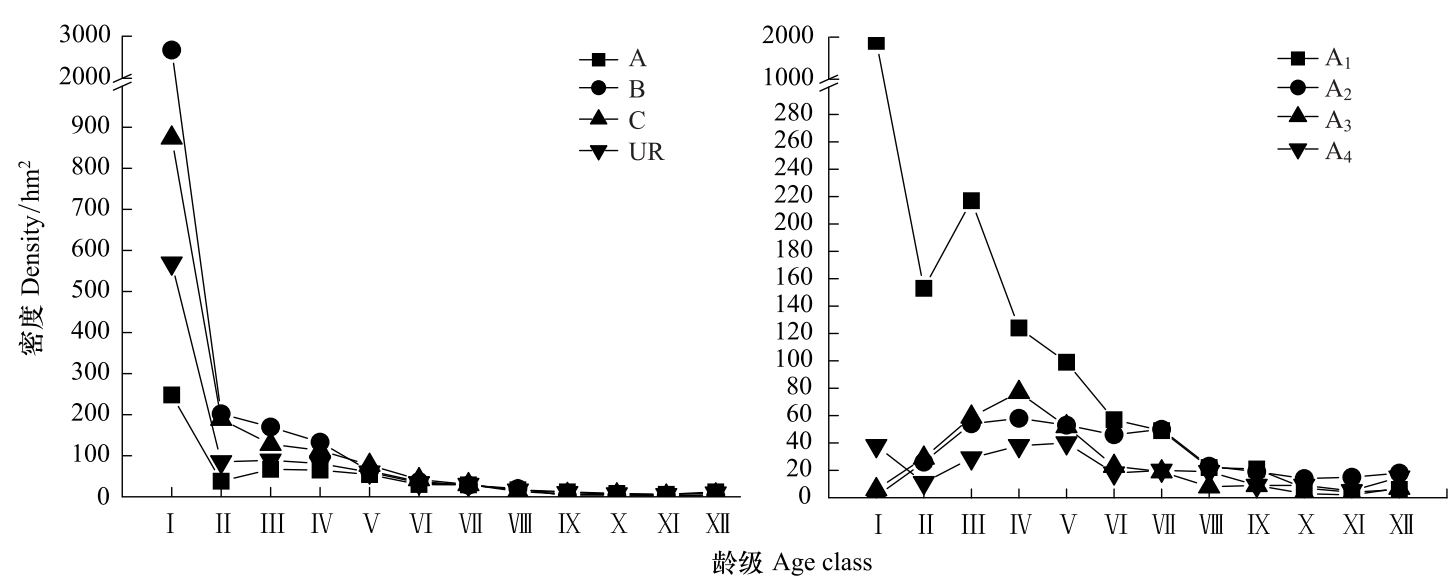

图 4 不同河段与同一河段不同生境胡杨种群密度动态

Fig.4 Density dynamics of P.euphratica populations under different sections and different habitats of the same section

3.4 塔里木河上游胡杨种群存活曲线特征分析 上段不同生境胡杨种群存活曲线明显不同。阿 瓦提胡杨种群存活曲线属典型“凹”型曲线, 托海乡、
南口镇种群总体属于 “凸” 型曲线, 而沙黑里克镇种 群存活曲线呈 “凹凸” 型变化 (图 5 )。上段、中段与 下段胡杨种群的存活数基本上随龄级增加而减少, 
但不同龄级的死亡率存在较大差异, 尤以第 I 龄级 死亡率最高 (图 5)。幼苗阶段个体较为丰富,成年 阶段相对稳定，存活曲线均属于“凹” (Deevey C) 型, 即属于增长种群。存活曲线斜率较大, 表明幼苗以 高死亡率为代价通过严酷环境篮的过滤和篎选, 此 后死亡率降低, 进人营养生长和生殖生长以完成其 整个生活史。为了更准确地确定各样地胡杨种群存 活曲线特征,采用线性回归分析 $(y$ : 标准化存活数; $x$ : 龄级), 配合直线回归方程并检验其显著程度 (表

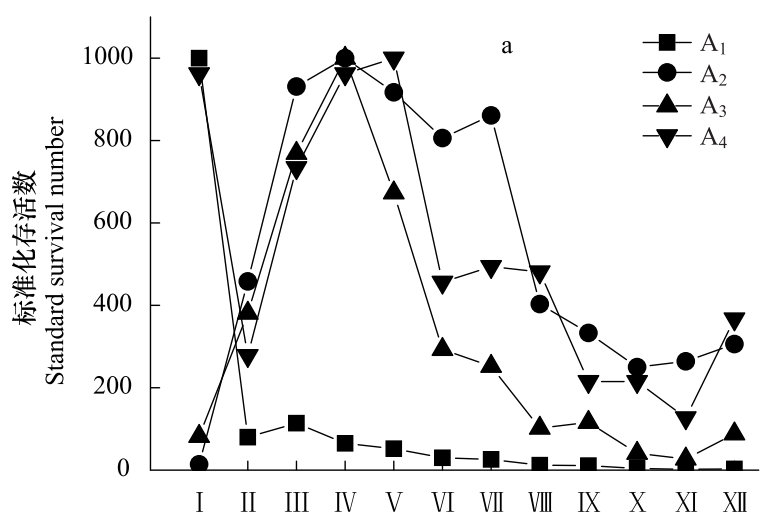

图 5 不同河段与同一河段不同生境胡杨种群的存活曲线

Fig.5 Survival curve of P.euphratica populations under different sections and different habitats of the same section

表 4 不同河段与同一河段不同生境胡杨种群存活曲线的线性回归方程

Table 4 Linear regression equation of the survival curve of $P$.euphratica populations under different sections and different habitats of the same section at the upper reaches of the Tarim river

\begin{tabular}{|c|c|c|c|c|}
\hline \multicolumn{2}{|c|}{$\begin{array}{c}\text { 地点 } \\
\text { Site }\end{array}$} & \multirow{2}{*}{$\begin{array}{l}\begin{array}{l}\text { 回归方程 } \\
\text { Regression equation } \\
y=-0.4693 x+6.2847\end{array}\end{array}$} & \multirow{2}{*}{$\begin{array}{c}\begin{array}{c}\text { 相关系数 } \\
\text { Correlation coefficient }\end{array} \\
0.9591\end{array}$} & \multirow{2}{*}{$\begin{array}{c}P \\
<0.01\end{array}$} \\
\hline A & $\mathrm{A}_{1}$ & & & \\
\hline & $\mathrm{A}_{2}$ & $y=0.0417 x+5.6786$ & 0.1285 & $>0.05$ \\
\hline & $\mathrm{A}_{3}$ & $y=-0.2099 x+6.5713$ & 0.6455 & $<0.05$ \\
\hline & $\mathrm{A}_{4}$ & $y=-0.1255 x+6.8876$ & 0.6713 & $<0.05$ \\
\hline B & & $y=-0.6157 x+6.3573$ & 0.9536 & $<0.01$ \\
\hline $\mathrm{C}$ & & $y=-0.4935 x+6.6751$ & 0.9680 & $<0.01$ \\
\hline
\end{tabular}

3.5 塔里木河上游胡杨种群结构的数量动态分析 基于种群动态量化方法对胡杨种群相邻大小级 间个体数量变化的动态量值 $\left(V_{n}\right)$ 计算表明, 塔里木 河上游胡杨种群各龄级间发育中,个体数量均呈现 上下波动变化 (表 5)。上段不同生境胡杨种群年龄 级间个体数量变化明显不同。托海乡、南口镇种群 在 I-IV 级发育中个体存活数量急剧下降 $\left(V_{n}<0\right)$, 尤其是幼苗向幼树、小树过渡中呈现明显的衰退结 构。阿瓦提与沙黑里克镇胡杨种群分别在 II - III 、
4)。由表 4 可知,上、中、下段及上段不同生境的胡 杨种群存活曲线除托海乡外,均表现出极显著或显 著的线性关系。因此,总体上中段、下段及上段的阿 瓦提胡杨种群为增长型, 上段的沙黑里克胡杨种群 为稳定型, 南口镇与托海乡胡杨种群为衰退型。究 其原因可能是南口镇、托海乡近年来大面积开荒造 田,较大的林斑变为农田,造成生境破碎化及林下土 壤表层盐分聚集,致使胡杨种群难以更新。

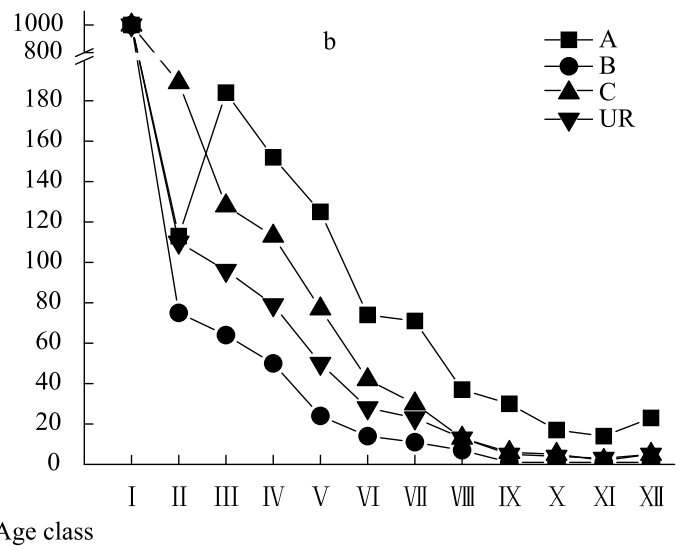

II $-\mathrm{V}$ 级过渡中呈明显衰退结构, 后者种群个体数 量衰退程度高于前者( 表 5)。上段不同生境胡杨种 群在老龄级发育中 $V_{n}<0$, 表明发育后期胡杨种群均 呈衰退结构。上段、中段与下段胡杨种群个体数量 动态变化略有不同, 上段 $V_{n}$ 变化仅在 II - III 级个体 发育过程中存活数量下降幅度较大。下段与中段均 在大、老龄级出现明显的个体数量下降,其它龄级则 表现个体数量增长态势 (表 5 )。 
表 5 不同河段与同一河段不同生境胡杨种群两相邻年龄级个体数量变化的动态量值 $\left(V_{n} / \%\right)$

Table 5 Dynamic values $\left(V_{n}\right)$ of P.euphratica populations under different sections and different habitats of the same section

\begin{tabular}{|c|c|c|c|c|c|c|c|c|c|c|c|c|}
\hline \multirow{2}{*}{\multicolumn{2}{|c|}{ 地点 Sites }} & \multicolumn{11}{|c|}{ 龄级 Age class } \\
\hline & & \multirow{2}{*}{$\begin{array}{c}\text { II } \\
91.95\end{array}$} & \multirow{2}{*}{$\begin{array}{c}\text { III } \\
-29.49\end{array}$} & \multirow{2}{*}{$\frac{\mathrm{IV}}{42.95}$} & \multirow{2}{*}{$\frac{\mathrm{V}}{20.22}$} & \multirow{2}{*}{$\frac{\mathrm{VI}}{42.25}$} & \multirow{2}{*}{$\frac{\text { VII }}{14.63}$} & \multirow{2}{*}{$\begin{array}{c}\text { VIII } \\
54.29\end{array}$} & \multirow{2}{*}{$\frac{\text { IX }}{6.25}$} & \multirow{2}{*}{$\frac{X}{66.67}$} & \multirow{2}{*}{$\frac{X I}{40.00}$} & \multirow{2}{*}{$\begin{array}{c}\text { XII } \\
-25.00\end{array}$} \\
\hline A & $A_{1}$ & & & & & & & & & & & \\
\hline & $\mathrm{A}_{2}$ & -96.97 & -50.75 & -6.94 & 8.33 & 12.12 & -6.45 & 53.23 & 17.24 & 25.00 & -5.26 & -13.64 \\
\hline & $\mathrm{A}_{3}$ & -78.57 & -50.44 & -23.13 & 32.65 & 56.57 & 13.95 & 59.46 & -11.76 & 64.71 & 33.33 & -69.23 \\
\hline & $\mathrm{A}_{4}$ & 71.05 & -62.07 & -23.68 & -3.80 & 54.43 & -7.69 & 2.56 & 55.26 & 0.00 & 41.18 & -65.52 \\
\hline B & & 92.45 & 15.70 & 21.57 & 52.50 & 42.11 & 22.73 & 29.41 & 91.67 & 0.00 & -50.00 & 50.00 \\
\hline C & & 78.39 & 32.38 & 11.88 & 31.74 & 45.22 & 27.91 & 56.45 & 55.56 & 8.33 & 63.64 & -63.64 \\
\hline
\end{tabular}

表 6 不同河段与同一河段不同生境胡杨种群年龄结构的动态指数 $\left(V_{p i} / \%\right)$

Table 6 Dynamic indices $\left(V_{p i}\right)$ of P.euphratica populations under different sections and different habitats of the same section

\begin{tabular}{|c|c|c|c|c|c|c|c|c|c|c|c|c|c|c|}
\hline \multirow{2}{*}{\multicolumn{2}{|c|}{ 地点 Sites }} & \multicolumn{13}{|c|}{ 龄级 Age class } \\
\hline & & \multirow{2}{*}{$\begin{array}{c}\text { II } \\
91.95\end{array}$} & \multirow{2}{*}{$\begin{array}{c}\text { III } \\
-2.20\end{array}$} & \multirow{2}{*}{\begin{tabular}{|c|}
$\mathrm{IV}$ \\
4.10
\end{tabular}} & \multirow{2}{*}{$\frac{\mathrm{V}}{1.05}$} & \multirow{2}{*}{$\begin{array}{c}\mathrm{VI} \\
1.67\end{array}$} & \multirow{2}{*}{$\begin{array}{c}\text { VII } \\
0.33\end{array}$} & \multirow{2}{*}{$\begin{array}{c}\text { VIII } \\
1.02\end{array}$} & \multirow{2}{*}{$\begin{array}{c}\mathrm{IX} \\
0.05\end{array}$} & \multirow{2}{*}{$\begin{array}{c}\mathrm{X} \\
0.53\end{array}$} & \multirow{2}{*}{$\begin{array}{c}\mathrm{XI} \\
0.10\end{array}$} & \multirow{2}{*}{$\begin{array}{c}\text { XII } \\
-0.04\end{array}$} & \multirow{2}{*}{$\begin{array}{c}V_{p i} \\
72.00\end{array}$} & \multirow{2}{*}{\begin{tabular}{|c|}
$V_{p i}{ }^{\prime}$ \\
0.003
\end{tabular}} \\
\hline A & $A_{1}$ & & & & & & & & & & & & & \\
\hline & $\mathrm{A}_{2}$ & -96.97 & -49.25 & -4.61 & 3.47 & 3.35 & -1.26 & 9.19 & 1.29 & 1.46 & -0.22 & -0.58 & 6.02 & 0.009 \\
\hline & $\mathrm{A}_{3}$ & -78.57 & -41.54 & -14.44 & 14.63 & 13.11 & 1.28 & 4.34 & -0.34 & 2.04 & 0.37 & -0.50 & 13.64 & 0.015 \\
\hline & $\mathrm{A}_{4}$ & 71.05 & -13.93 & -8.81 & -1.24 & 13.83 & -0.80 & 0.26 & 4.95 & 0.00 & 1.53 & -1.40 & 17.38 & 0.037 \\
\hline B & & 92.45 & 1.10 & 1.20 & 2.20 & 0.82 & 0.25 & 0.25 & 0.55 & 0.00 & -0.03 & 0.05 & 80.13 & 0.003 \\
\hline C & & 78.39 & 5.76 & 1.27 & 2.74 & 2.52 & 0.83 & 1.18 & 0.50 & 0.03 & 0.23 & -0.08 & 58.67 & 0.006 \\
\hline
\end{tabular}

进一步对整个胡杨种群年龄结构的数量变化动 态指数 $\left(V_{p i}\right)$ 计算表明, 上段不同生境胡杨种群动态 指数明显不同 (表 6 )。南口镇与托海乡、沙黑里克

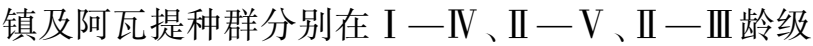
发育中显著下降, 同时老龄级 $(X I-X I I)$ 明显下降, 尤 其托海乡、南口镇胡杨幼苗向幼树发育中显著衰退。 但从不同生境胡杨种群整体动态指数看, $V_{p i}>0$, 表明 各生境下虽然种群前期受到环境篎的强烈过滤导致 种群数量大幅波动,但总体仍呈相对稳定状态。上 段胡杨种群在 II - III XI-XII级发育过程中种群存 活数动态指数均为负值, 表明胡杨种群幼树发育因 受到强烈环境篮的过滤, 存活数量下降; 中龄、大老 龄发育过程中整体表现为衰退的结构动态关系。总 体来看, 上段、中段与下段整个种群动态指数 $V_{p i}$ 均 为正值 (表 6), 表明胡杨种群整体呈增长趋势, 这与 图 2 分析结果一致。考虑种群受未来外部环境干扰 时,上段不同生境及中段、下段胡杨种群的龄级结构 动态指数 $\left(V_{p i}{ }^{\prime}\right)$ 均大于 0 , 尤其上段 $\mathrm{A}_{2} 、 \mathrm{~A}_{3} 、 \mathrm{~A}_{4}$ 种群的 $V_{p i}{ }^{\prime}$ 明显较大 (表 6 ), 表明上段胡杨种群受环境影响 较大, 对环境变化较敏感。
3.6 塔里木河上游胡杨种群的时间序列预测

以塔里木河上游不同生境胡杨种群各龄级株数 为原始数据, 按照一次平均推移法预测出各龄级在 未来 $10 、 20 、 30 \mathrm{a}$ 后的株数, 将结果绘成龄级与个体 数的关系图(图 6、图 7)。上段 4 个不同生境胡杨种 群的数量动态明显不同 (图 6)。阿瓦提县胡杨种群 各龄级株数的峰值在时间序列预测中依次向后推 移, 幼龄数量减少, 大径级个体数逐渐增多 (图 6)。 由于其幼龄株数丰富, 能够补充后期各龄级, 表明未 来种群呈增长趋势。托海乡与南口镇胡杨种群动态 表现相似, 小龄级 $(\mathrm{I}-\mathrm{IV})$ 数量减少, $\mathrm{V}$ 龄级后数量 明显增加, 尤其未来 $20 \mathrm{a} V I$ 、 VII 龄级和 30a VIII龄级显 著增多,其后均呈下降趋势 (图 6)。由于大、老龄级 数量稳步上升, 而小龄级株数逐步下降, 表明随着时 间推移, 托海乡与南口镇胡杨种群将走向衰退。沙 黑里克镇胡杨种群在未来 $10 、 20$ 与 $30 \mathrm{a}$ II 、 IV 和 VI 龄级分别比初始种群数量下降了 $35.53 \%$ 、23.68\% 和 $23.68 \%$, 未来 $20 \mathrm{a}$ VI 、VII龄级个体数达最高 (图 6), 种群龄级向大老龄级发展。因此, 沙黑里克镇胡杨 种群幼龄不足且生长发育过程中受到严酷环境篎的 过滤, 致使小龄级缺失, 大老龄级个体显著增多, 未 
来种群将走向衰退。

塔里木河上游及各段胡杨种群各龄级株数峰值 在时间序列预测中依次向后推移,多数种群的 I 龄 级个体数随着时间推移逐渐减少, 中大龄级个体数 逐渐增多, 在 VII龄级以后胡杨种群进人成熟阶段, 数 量相对稳定 (图 7)。由于中、下段幼龄个体数丰富, 种群具有充足的后备资源, 能够补充在中龄阶段由 于种内、种间竞争而减少的个体数。如果未来能维 持现有生境状况，中、下段胡杨种群呈稳定增长趋

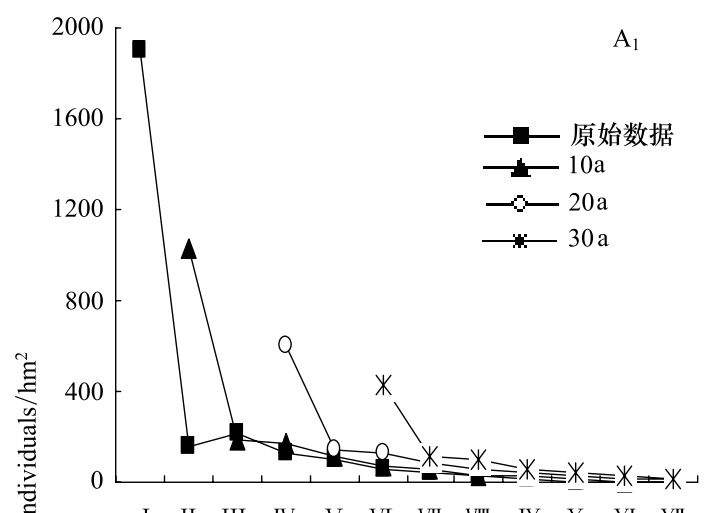

$\begin{array}{llllllllllll}\text { I } & \text { II } & \text { III } & \text { IV } & \text { V } & \text { VI } & \text { VII } & \text { VIII } & \text { IX } & \mathrm{X} & \text { XI } & \text { XII }\end{array}$

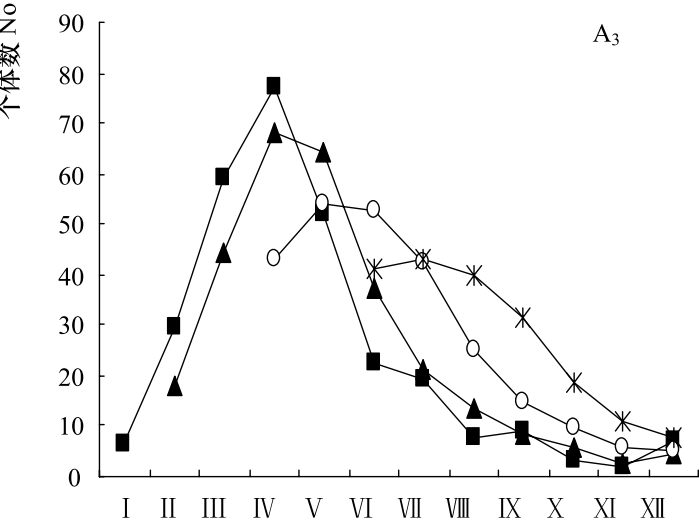

势。但是上段与中、下段表现不同,未来 $10 \mathrm{a}$ 上段胡 杨种群 III 、 IV 龄级个体数明显减少, 其后各龄级数量 有所增加 (图 7), 表明幼树生长过程中受到强烈环 境篮的过滤作用, 导致小树死亡率较高, 这将影响上 段胡杨种群的发展。同时,未来 $20 、 30$ a 上段种群大 龄级个体数量显著增多,幼龄个体供应不足。如果 上段人们开荒造田、过渡利用水资源的行为得不到 有效控制,胡杨种群势必走向衰落。
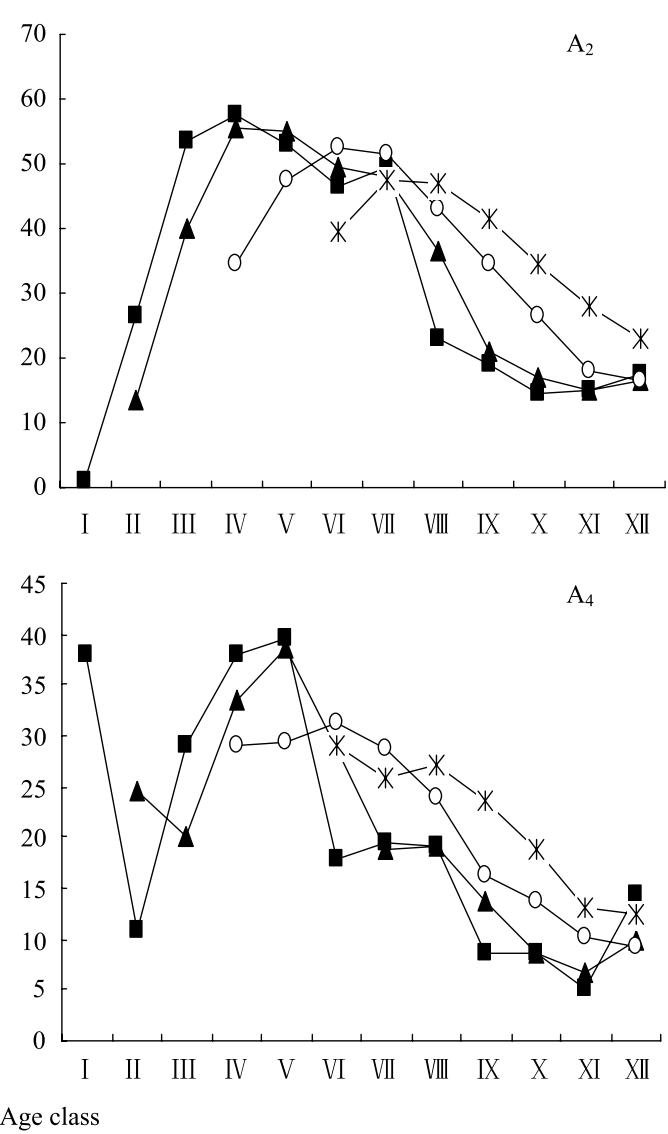

图 6 上段不同生境胡杨种群数量动态的时间序列预测

Fig.6 Time sequence prediction of P.euphratica populations under different habitats of the upper section
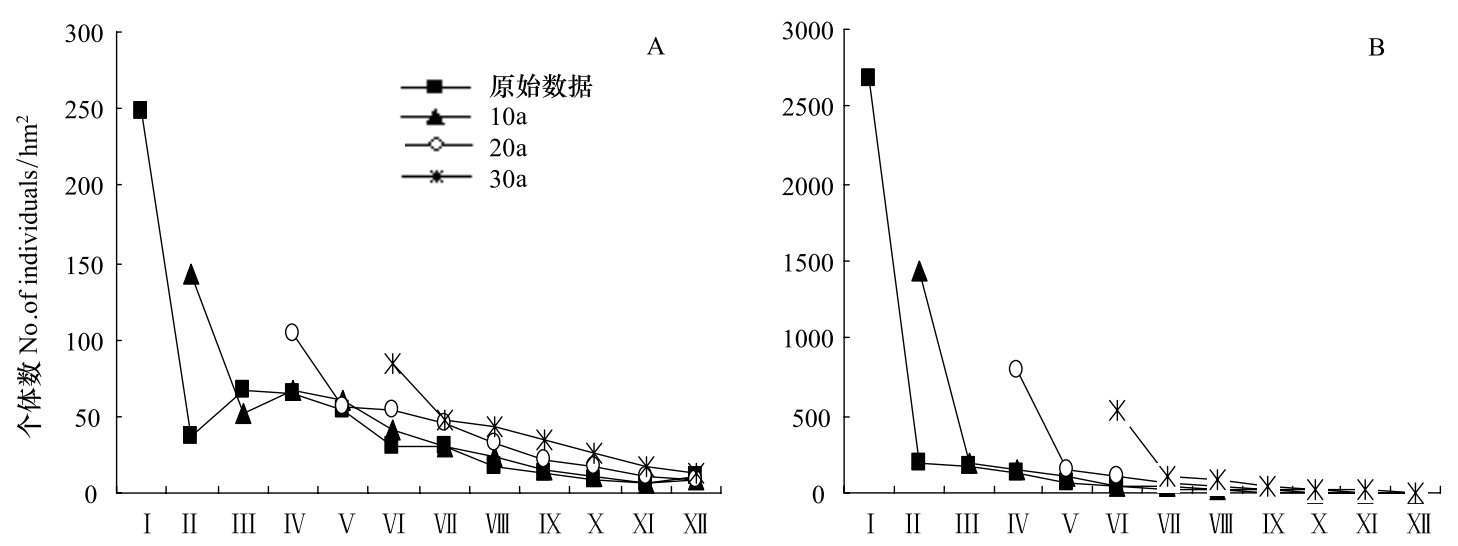

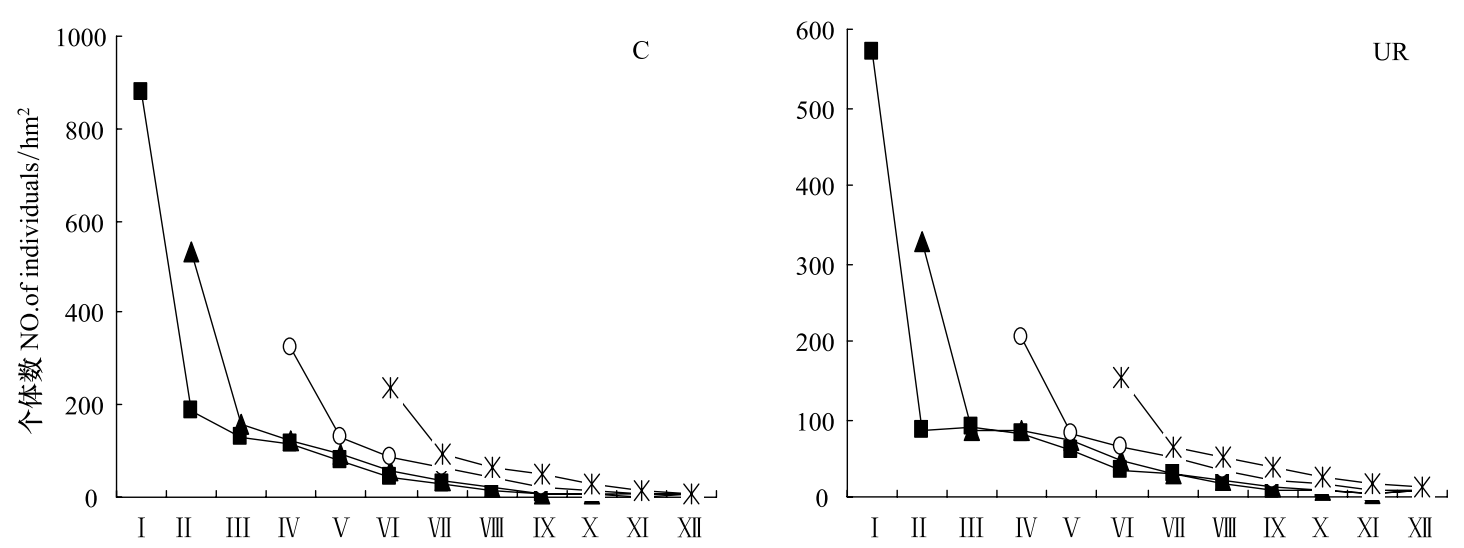

图 7 塔里木河上游不同河段胡杨种群数量动态的时间序列预测

Fig.7 Time sequence prediction of P.euphratica populations under different sections at the upper reaches of the Tarim River

\section{4 讨论}

植株的径级结构可以反映该种群个体在空间和 时间上的配置差异。种群径级结构和高度分析是揭 示种群生存现状和更新策略的重要途径之一 ${ }^{[17]}$ 。 塔里木河上游中、下段胡杨种群幼苗更新资源充足， 年龄结构均呈上窄下宽的金字塔型, 属增长种群, 而 上段胡杨种群结构在 II 龄级存在明显凹陷且生长发 育过程中幼苗死亡率较高, 如果没有幼龄个体对中 龄株数的补充,上段胡杨种群整体长期稳定性将难 于维持。上段不同生境胡杨种群年龄结构差异明 显,越远离河道胡杨种群幼龄比例越低、退化越明 显。造成上段胡杨更新幼苗缺失的原因是人类大量 开荒、水资源过度利用导致胡杨更新发生障碍。托 海乡、沙黑里克与南口镇河岸附近的天然植被由于 开艮农田均被破坏, 大部分残存的胡杨林靠近塔克 拉玛干沙漠,生境恶劣, 种子下落难以萌发, 仅可见 少量根蔝苗; 加之极端干旱气候, 蒸发量大, 沙漠化 加剧, 胡杨生存环境日益恶劣, 长势较差。此外, 人 工灌溉截流致使洪水漫野横流的自然过程受到抑 制,不仅使天然洪水水面携带种子的能力骤降,也影 响了种子萌芽与幼苗的形成。可见,人类不合理的 资源利用致使胡杨种子繁殖困难、幼苗无法向幼树 阶段转换已成为制约胡杨种群更新和发展的“瓶 颈”。

植物种群的存活曲线分析可以反映种群现实状 况、展现植物种群与环境的竞争关系 ${ }^{[8]}$ 。时间序列 分析具有较高的预测准确性, 是种群动态预测的理 想手段 ${ }^{[18]}$ 。中段、下段胡杨种群个体存活曲线均呈
“凹”型, 属增长种群。但存活曲线斜率较大、幼龄死 亡率高; 成年阶段相对稳定, 存活率高。中段胡杨平 均存活率最大,上段存活率最小。上段不同生境胡 杨种群存活曲线差异明显, 存活曲线随离河岸距离 增加由“凹”型转变为“凸”型, 表明中、大树存活率 较高, 幼树与老树成活率低。这与胡杨种群的幼苗 资源、存活状态以及胡杨的生物生态学特性及生境 有关。在干旱荒漠区, 水分是植物生长存活的必要 条件, 尤其是幼苗、幼树阶段需要较多的土壤水分, 而林内土壤水分条件较差、不能满足所有植株生长 需要将导致种内竞争激烈, 空间生态位受到限制, 这 是抑制胡杨幼苗向幼树转化及幼树成活的主要原 因。上游靠近河岸及河漫滩胡杨幼苗数量较多, 密 度较大, 但自疏与他疏作用及放牧、化感作用 ${ }^{[19]}$ 致 使幼树转化的成活率降低。远离河岸胡杨种群幼苗 贾乏, 第 $\mathrm{IV} 、 \mathrm{~V}$ 龄级出现峰值是由于随着年龄增长及 生境恶化,种群抗性及适应环境的能力随之减弱, 对 于胡杨种群来说其利用土壤养分、水分等条件的生 长能力下降, 使种群的存活数与存活率开始下降。 时间序列分析也表明上段远离河岸的胡杨种群幼龄 级数量锐减, 大龄级数量明显增多, 种群向大老龄 级发展。因此,上段远离河岸的南口镇、托海乡与沙 黑里克镇胡杨种群将会随时间推移和人类水土资源 开发加剧而加速衰退。因此, 今后应采用适当的人 工辅助恢复措施、保护现有植株及其生境是保持塔 里木河流域胡杨种群自然更新和恢复的关键。

\section{References:}

[ 1 ] Liu P X. Study on population structure and dynamics of Populus euphratica in the middle and lower reaches of the Shule river basin 
oasis, Hexi Corridor. Journal of Natural Resources, 2011, 26 (3) : 429-439.

[ 2] Fuchs M A, Krannitz P G, Harestad A S. Factors affecting emergence and first-year survival of seedlings of Garry oaks (Quercus garryana) in British Columbia, Canada. Forest Ecology and Management, 2000,137(1/3):209-219.

[ 3 ] Armesto J J, Casassa I, Dollenz O. Age structure and dynamics of Patagonian beech forests in Torres del Paine National Park, Chile. Vegetatio, 1992, 98(1):13-22.

[ 4] Wang S J. The status, conservation and recovery of global resources of Populus euphratica. World Forestry Research, 1996,9 (6) $: 37-44$.

[ 5 ] Deng C Z, Zhang X M, Wu J X, Zhu J T, Wei J.The influence of water conveyance embankments on the Populus euphratica's communities and populations in the middle reaches of Tarim River. Acta Ecologica Sinica, 2010, 30(5) : 1356- 1366.

[ 6 』 Chen Y N, Chen Y P, Li W H, Zhang H F. Response of the accumulation of proline in the bodies of Populus euphratica to the change of groundwater level at the lower reaches of Tarim River. Chinese Science Bulletin, 2003, 48(9):958-961.

[ 7 ] Wu J X, Zhang X M, Li L, Deng C Z, Liu G J, Wu G Y. Characteristics and dynamics analysis of Populus euphratica populations at the middle reaches of the Tarim river. Arid zone research, 2010,27(2):242-248.

[ 8 ] Wang J S, Halik U, Cyffka B, Osman K, Peng S H. Study on DBH-structure of Populus euphratica and their spatial distribution in the lower reaches of the Tarim River. Chinese Bulletin of Botany, 2008, 25(6):728-733.

[ 9 ] Deng C Z, Zhang X M, Li L, Wu J X, Zhu J T, Liang S M, Lü C Y. Community characteristics and population structure of Populus euphratica Oliv in lower reaches of Tarim River. Journal of Desert Research, 2010, 30(3) :589-595.

[10] Li X K, Su Z M, Xiang W S, Ning S J, Tang R Q, Ou Z L, Li R T. Study on the structure and spatial pattern of the endangered plant population of Abies yuanbaoshanensis. Acta Ecologica Sinica, 2002, 22(12):2246-2253.

[11] Frost I, Rydin H. Spatial pattern and size distribution of the animal-dispersed quercus rubur in two spruce-dominated forests. Ecoscience, 2000,7(1) : 38-44.

[12] Yu Q, Xie Z Q, Xiong G M, Chen Z G, Yang J Y. Community characteristics and population structure of dominant species of Abies fargesii forests in Shennongjia National Nature Reserve. Acta Ecologica Sinica, 2008, 28(5):1931-1941.

[13] Deevey E S Jr. Life tables for natural populations of animals. The Quarterly Review of Biology, 1947, 22(4):283-314.

[14] Chen X D.A study on the method of quantitative analysis for plant population and community structural dynamics. Acta Ecologica Sinica, 1998, 18(2):214-217.

[15] Xie Z J. Time Sequence Analysis. Beijing: Beijing University Press, 1990.

[16] Xiao Y N, He P, Li X H, Deng H P. Study on numeric dynamics of natural populations of the endangered species Disanthus cercidifolius var. Longipes. Acta Phytoecologica Sinica, 2004, 28
(2) : 252-257.

[17] Wang Z F, An S Q, Zhu X L. Distribution pattern of tree populations in tropical forest and comparison of its study methods. Chinese Journal of Applied Ecology, 1998, 9(6) : 575-580.

[18] Wu C Z, Hong W. Multidimensional time series analysis on tree growth. Chinese Journal of Applied Ecology, 1999, 10 (4): 395- 398.

[19] Ma Y Q, Liao L P, Yang Y J, Wang S L, Gao H, Chen C Y, Liu G Y. Effect of vanillin on the growth of Chinese fir (Cunninghamia lanceolata) seedlings. Chinese Journal of Applied Ecology, 1998, 9(2) :128-132.

\section{参考文献:}

[1] 刘普幸.疏勒河中下游绿洲胡杨种群结构与动态研究. 自然资 源学报,2011,26(3) :429-439.

[ 4 ] 王世绩.全球胡杨林的现状及保护和恢复对策.世界林业研究, $1996,9(6): 37-44$.

[ 5 ] 邓潮洲, 张希明, 吴俊侠, 朱军涛, 魏疆. 输水堤坝对塔里木河 中游胡杨群落及种群的影响. 生态学报, 2010, 30 (5): 1356-1366.

[6 ] 陈亚宁,陈亚鹏, 李卫红, 张宏锋. 塔里木河下游胡杨脯氨酸累 积对地下水位变化的响应.科学通报,2003,48(9) : 958-961.

[ 7 ] 吴俊侠,张希明,李利,邓潮洲,刘国军,武广洋.塔里木河干流 中游胡杨种群特征与动态分析. 干旱区研究, 2010,27(2): 242-248.

[ 8 ] 王金山,哈力克 - 玉米提,Cyffka B,吾斯曼 - 库尔班,彭树宏. 塔里木河下游胡杨林胸径结构及林木分布特征. 植物学通报, 2008,25 (6) : 728-733.

[9]邓潮洲, 张希明, 李利, 吴俊侠, 朱军涛, 刘国军, 吕朝燕. 塔里 木河下游胡杨群落特征及种群结构分析. 中国沙漠, 2010,30 (3) :589-595.

［10］李先琨,苏宗明, 向悟生, 宁世江, 唐润琴, 欧祖兰, 李瑞棠. 濒 危植物元宝山冷杉种群结构与分布格局.生态学报, 2002,22 (12) :2246-2253

[12］于倩,谢宗强, 熊高明, 陈志刚, 杨敬元. 神农架巴山冷杉林群 落特征及其优势种群结构.生态学报,2008,28(5): 1931- 1941.

[14] 陈晓德. 植物种群与群落结构动态量化分析方法研究.生态学 报, 1998,18(2):214-217.

[15] 谢衷洁.时间序列分析. 北京: 北京大学出版社, 1990 .

[16] 肖宜安, 何平, 李晓红, 邓洪平. 濒危植物长柄双花木自然种群 数量动态. 植物生态学报, 2004,28(2) : 252-257.

[17] 王峥峰,安树青, 朱学雷.热带森林乔木种群分布格局及其研 究方法的比较.应用生态学报, 1998,9(6):575-580.

[18] 吴承祯,洪伟.林木生长的多维时间序列分析. 应用生态学报, 1999,10 (4) :395- 398 .

[19］马越强,廖利平, 杨跃军, 汪思龙, 高洪, 陈楚䒯, 刘更有.香草 醛对杉木幼苗生长的影响. 应用生态学报, 1998, 9 (2): 128- 132 . 